\title{
El Problema de la cientificidad del Derecho en la concepción de Ciencia de La Modernidad: Una aproximación al Investigar Jurídico*
}

Leider Gómez Caballero**

Estudiante

Facultad de Derecho / Universidad de Cartagena

Artículo recibido: 15/03/2010 Aprobado: 30/04/2010

leidergo@hotmail.com

\section{RESUMEN}

Dentro de la historia de la ciencia ha aparecido la física (physis-estudio de la naturaleza) como uno de los saberes más fecundos y que mas rápido ha encontrado el verdadero camino de una ciencia, al decir de Kant (1987), debe la física tan provechosa revolución de su pensamiento a la ocurrencia de buscar (no imaginar) en la naturaleza, conforme a lo que la misma razón ha puesto en ella. En este sentido la física ha sido la ciencia que les ha marcado el derrotero a todas las demás y ha puesto, en diversas ocasiones a replantear saberes externos a ella. El objeto del presente ensayo es describir cómo colateralmente al desarrollo de la física se ha dado también un desarrollo o más bien una transformación del concepto de ciencia y una transformación de aquellos saberes que aspiraron a encuadrar en el nuevo concepto de ciencia; entre estos el derecho. Como corolario de este proceso de intento de formalizar el saber jurídico, surgen muchas escuelas que intentan explicar el investigar jurídico. La experiencia jurídica contemporánea nos muestra que el objeto del estudio jurídico es un objeto que cambia con el tiempo y con las culturas, y la exigencia de un método fundado en la teoría de la interpretación y argumentación surgen como conclusiones-premisas de esta investigación.

\section{PALABRAS CLAVE}

Ciencia de la modernidad, física, ley científica, método cartesiano, jurisprudencia, derecho.

\section{ABSTRACT}

Within the history of science has emerged physics (physis, nature study) as one of the most prolific and knowledge faster has found the true path of a science, saying Kant (1987) the reason for so profitable physics revolution of their thinking is in the occurrence of search (not imagine) in nature, as the same reason it has been In this sense, physics was the science that has made them the route to all others and has on several occasions to rethink knowledge external to it. The purpose of this essay is described as collateral to the development of physics has also given development or rather a transformation of the concept of science

* El presente artículo surge como resultado de una investigación madre denominada: “Historia de la ciencia y el derecho: Roma, Grecia y la modernidad". Estudiante Coordinador de la Investigación: Leider Gómez Caballero.

** Estudiante de octavo semestre de la facultad de derecho y ciencias políticas de la Universidad de Cartagena. Miembro del semillero de investigación de filosofía del derecho e interpretación constitucional. En la actualidad la línea de investigación es: "El control racional de la constitución: test de ponderación y balanceo". 
and a transformation of the knowledge that aspired to frame the new concept of science, among which the law, as a corollary of this process attempt to formalize the legal knowledge arise many theories that attempt to explain the legal research. The contemporary legal experience shows us that the object of legal study is an object that changes over time and cultures, and the need for a method based on the interpretation and argumentation theory appears as a conclusions-premises from this research.

\section{KEYWORDS}

Modernity science, physics, scientific rule, Cartesian method, jurisprudence, law.

\section{INTRODUCCIÓN}

En el presente ensayo, el lector encontrará en un primer momento, un desarrollo del concepto de ciencia que introdujo la modernidad, una breve reseña histórica que servirá como corolario para explicar los principales problemas que trajo el nuevo concepto de ciencia, una ciencia que habla en un lenguaje matemático y reduce su objeto a lo que es perceptible, entendiendo todo objeto de conocimiento conforme a lo que la diosa razón dicta. En un segundo momento, se abordará cuál fue el papel del derecho frente al nuevo paradigma científico, ¿Cómo era el derecho antes de entrar la modernidad?, esta será una pregunta necesaria para entender los problemas que más adelante se le iban a presentar desde el punto de vista teórico: desarrollaremos los principales intentos de acomodar el concepto de derecho en el concepto de ciencia, es decir, elevar al derecho a la categoría de ciencia. Finalmente el lector encontrará que muchos de los problemas que tenemos hoy en la investigación jurídica y problemas a la hora de resolver problemas de derecho, tienen como causa el proceso histórico planteado.

Con respecto a la metodología, este ensayo es producto de una investigación bibliográfica, cualitativa, descriptiva y la etapa histórica tomada como marco de referencia para el presente ensayo, es el renacimiento entendido no sólo como un problema de arte sino como un cambio cultural e histórico de repercusiones profundas, cambio que se da como una respuesta al oscurantismo y las instituciones de la edad media. El renacer del hombre fue visto no como el nacer a una vida diferente y superhumana sino, el nacer a una vida verdaderamente humana, fundada en aquello que tiene el hombre como propio: las artes, las ciencias y la investigación, que hacen de él un ser distinto de todos los demás seres de la naturaleza, un ser preponderante tal cual lo entendieron los griegos, de esta forma el renacimiento trae consigo un abandono a esa vida de contemplación sumisa de Dios y una centralización del hombre y con él las artes y las ciencias(Abbagnano,1995).

Célebre es la carta que le envía Newton a su par científico Robert Hooke en 1675 dentro de las polémicas que mantenían estos dos científicos acerca de la famosa ley de gravitación universal; al respecto le escribió Newton "Si he visto más lejos es porque estoy sentado sobre los hombros de gigantes", lo que ilustra la frase es que si bien podemos ubicar a Newton como el punto de cierre de la revolución científica moderna, él mismo reconoció que antes de él existieron muchos físicos que fueron quienes plantaron las bases de la ciencia de la modernidad, tales como Copérnico, Kepler, Brahe y Galileo entre muchos otros, dejando presente: $\left.1^{\text {era }}\right)$ Que una revolución científica no es obra de una sola persona, que es producto de muchos cambios cualitativos a nivel de toda la sociedad, y $2^{\text {da }}$ ) Que la ciencia es un producto cultural, es un concepto que no se aparta ni de la sociedad ni de la cultura, de esta forma cambios profundos a nivel de ciencia son efecto de cambios profundos a nivel social, económico y político, como en efecto lo fue el renacimiento. 


\section{LOS GIGANTES DE LAMODERNIDAD}

De esta manera haremos mención de los gigantes como los llamó Newton como condición necesaria para el entendimiento del contexto de descubrimiento del nuevo tipo de razón que va a traer la modernidad.

1. Nicolás Copérnico. 1473 - 1543: Convencionalmente ha sido lugar común admitir que la modernidad empieza con Copérnico y su llamada "revolución copernicana". Parte del principio pitagórico-platónico de la estructura matemática del universo para llegar a una exacta formulación matemática de la nueva cosmología, se encargará de refutar el supuesto geocéntrico; formulará la tesis según la cual la tierra gira sobre sí misma y alrededor del sol, además concluye que no es la tierra el centro del universo sino el sol en torno al cual giran los planetas.

Demostró también cómo a su vez sus cálculos matemáticos se simplificaban prestándose fácilmente a explicar la observación astronómica. De esta manera, vemos como ya en Copérnico se daba un asomo de la utilización de un lenguaje matemático como presupuesto de la nueva ciencia. Copérnico es una ruptura en el modo de conocer el universo y en el modo de ejecutar la mecánica de hacer ciencia, a saber, una revolución científica y una revolución epistemológica (Mercado, 1998), en esto consiste el giro Copernicano.

2. Johannes Kepler. 1571-1630: Las observaciones de Tycho Brahe permitieron a Kepler descubrir sus leyes y corregir de esta forma la doctrina de Copérnico, el cual admitía el movimiento circular de los planetas alrededor del sol. Kepler negará el supuesto griego sobre la existencia de movimientos circulares, dirá que el movimiento de los cuerpos celestes es elíptico y el sol ocupa uno de los focos de le elipse [primera ley de Kepler]; las áreas descritas por el rayo vector y el segmento de recta que une el planeta con el Sol son proporcionales al tiempo empleado en recorrerlas[segunda ley de Kepler]; los cuadrados de los tiempos empleados por los diversos planetas en recorrer enteramente sus órbitas, se relacionan entre sí con los cubos de los ejes mayores de las elipses descritas por los planetas [tercera ley de Kepler]. El universo Kepleriano se halla jerárquicamente estructurado en relación al sol y armoniosamente ordenado por el creador, lo que muestra en él todavía una cierta influencia teológica, no obstante sigue a Copérnico en la consideración matemática y geométrica del cosmos; al respecto dice Abbagnano (1995): "Pero el descubrimiento de Kepler confirmaba definitivamente el valor del procedimiento que reconoce en la proporción matemática la verdadera objetividad natural" (p.147).

3. Galileo Galilei. 1564-1642: Galileo encarna el prototipo del científico moderno, exento de magias y concepciones teológicas. "Solamente el libro de la naturaleza es el objeto propio de la ciencia; y este libro es interpretado y leído solamente por la experiencia. La experiencia es la revelación directa de la naturaleza en su verdad" (Abbagnano, 1995, p. 149).

Sobre la estructura matemática de la realidad objetiva, Galileo sostiene que el libro de la naturaleza está escrito en lenguaje matemático y sus caracteres son triángulos, círculos y otras figuras geométricas.

Dos son los puntos nodales en galileo. $1^{\text {ero }}$ La naturaleza como objeto único de conocimiento de la ciencia, aprehensible solo experimentalmente $y$, $2^{\text {do }}$ ) Ese libro único llamado naturaleza está escrito en lenguaje matemático, de esta forma el científico moderno debe ser un verdadero matemático si aspira a entender la naturaleza.

Hasta este punto la construcción de lo que iba a llamarse ciencia de la modernidad llevaba conquistado lo siguiente:

1. El único objeto de estudio válido de la nueva ciencia es la naturaleza, aprehendida sensorialmente.

2. Su lenguaje es el matemático, la cientificidad queda reducida de esta forma a aquello que sea susceptible de expresar por medio de una ecuación.

3. Con Copérnico la modernidad introduce una nueva forma de contemplar el universo. (el heliocentrismo desplaza al geocentrismo). 
4. La ciencia moderna declara su independencia de la teología y reivindica el papel del hombre frente a su mundo, se deja de lado aquella vida contemplativa y se reemplaza por una vida donde el hombre ocupa el centro, tal y como lo entendieron los griegos. (El antropocentrismo desplaza al teocentrismo).

Este era el avance que había obtenido la ciencia naciente en el siglo $\mathrm{XV}$ y principios del $\mathrm{XVI}$; no obstante, dicho modelo de ciencia no se encontraba depurado en su totalidad y su proceso de desenvolvimiento se ve abruptamente frenado por el ciclo de guerras de religión que prácticamente se consumieron todo el siglo XVI. No es objeto de este análisis el estudio de las guerras de religión, solo es menester indicarlo como un suceso que detuvo de manera parcial el proceso de refinamiento de la ciencia moderna.

Luego de finiquitadas dichas guerras, se recupera la posibilidad de seguir pensando y en términos más específicos de seguir el proceso de depuración de la ciencia de la modernidad. Para esta época ya empezaban a ocurrir cosas interesantes. Newton dentro de sus estudios sobre la óptica trato un problema que venía del siglo XIII, es el referente a la reflexión y refracción de la luz, explicando el famoso problema del bastón quebrado.

El experimento ya famoso consiste en tomar un recipiente con agua en su interior, al introducir el bastón nuestros ojos lo perciben roto y al sacarlo, está entero. Este es el llamado fenómeno de refracción de la luz, y se debe a que al pasar la luz de una sustancia a otra, por ejemplo de aire a agua, cambia su velocidad, lo que tiene como consecuencia que el haz cambie su dirección. Los fenómenos de refracción se incorporan a la óptica geométrica, simplemente suponiendo que los rayos luminosos cambian de dirección no sólo al reflejarse sino también al pasar de un medio refringente a otro; por ejemplo, del agua al aire, 0 del agua al vidrio, o del vidrio al aire.

En palabras más sencillas, la parte de luz que pasa a la nueva sustancia se refracta y crea la ilusión a nuestra vista de la ruptura del bastón. Todos estos fenómenos hasta ahora inexplicables estaban siendo satisfechos por los físicos del siglo XVII, y la física, siendo fiel al estudio de la naturaleza, se mostraba como una de las más fértiles ciencias, pero estos experimentos de avanzada para la época empezarían a crear distorsiones en otras ramas del saber, especialmente este experimento de refracción de la luz empezaría por retumbar en la mente de los filósofos.

\section{LARELACIÓN DE CONOCIMIENTO}

Con el experimento anteriormente mencionado fueron muchas las consecuencias que se derivaron a nivel filosófico. Hasta este punto histórico la relación de conocimiento estaba constituida por un sujeto que aprehendía la realidad por medio de sus sentidos, relación de conocimiento que se podía materializar con el método deductivo y posteriormente, con Aristóteles, por el inductivo. Lo importante es que el sujeto cognoscente estaba en conexión directa con el objeto conocido, por medio de los sentidos bien fuera deductiva 0 inductivamente y la verdad no era más que una relación de correspondencia entre lo captado por los sentidos y los hechos. Este era el llamado método subjetivo, donde el sujeto necesariamente interactuaba con la naturaleza en el proceso de conocimiento, prueba de esto es el concepto de episteme ${ }^{1}$ ynous ${ }^{2}$ griego $^{3}$.

\footnotetext{
${ }^{1}$ La palabra episteme es una palabra griega que fue traducida por los romanos al latín como tientia, a su vez ciencia, pero ¿Qué entendían los griegos por episteme?El verbo epistemai significa erguirse, pararse; los griegos lo aplicaban a partir del perfeccionamiento de la condición humana a la posibilidad que se adquiría para cada uno de nosotros de conocer a fondo una cosa, cualquier problema de conocimiento, es un conocimiento a fondo de algo. Por eso es que modernamente esa palabra se traduce como conocimiento. Una vez nos erguíamos sobre la cosa, eso implicaba que éramos más éticos que el común de los demás y que habíamos logrado controlar los instintos, emociones y pasiones, todo en pos de recorrer el camino que llevaba a la sofia.

${ }^{2}$ Esta palabra la tradujeron los romanos al latín como intus leyere, leer al interior, lectura intima; implica un concepto en el cual la cosa objeto del conocimiento y el sujeto cognoscente llegaban a estar tan íntimamente relacionados que el individuo no solo se erguía sobre ella sino que la incorporaba a su propia condición, en esta etapa ya hay una transformación del intelecto; intus leyere evolucionó en inteligencia.

${ }^{3}$ Los conceptos de episteme y nous, en el pensar griego se encuentran como escalones a los que llega el hombre en la medida que es un ser ético, que construye su vida, el arte, la prudencia, la ciencia, la inteligencia son todos aptitudes del espíritu y escalones para llegar al máximo grado de eticidad griega, a saber, la Sofía, la sabiduría.
} 
Pues bien, a partir de los experimentos sobre la luz que haría Newton, este esquema necesariamente tendría que colapsar, porque con la refracción de la luz estábamos en capacidad de demostrar cartesianamente que nuestros sentidos en ocasiones nos mandan imágenes que no corresponden con la realidad, es decir, que nuestros sentidos están expuestos al error, nuestros sentidos se equivocan. A partir de estas consideraciones se presentarían muchos interrogantes tortuosos para la filosofía.

A partir de las leyes de la óptica desarrolladas en el siglo XVII, la filosofía se vio obligada a plantearse el problema del conocer, del cómo se conoce y que certeza hay de lo que se conoce en virtud del error intrínseco que apareja nuestros sentidos, es decir, su existencia como saber válido se vio condicionada a la creación de una teoría del conocimiento. En este orden de ideas la modernidad deberá romper con la antigua relación sujeto que conoce-realidad cognoscible donde el sujeto interactúa con la realidad, ahora esta "realidad cognoscible" se llamaría "objeto", algo separado totalmente del sujeto porque es el sujeto quien lleva a cuestas de manera natural el error de sus sentidos. Descartes (1999) sistematizará todo este problema precedentemente planteado por el error de los sentidos.

El método cartesiano tiene su origen básicamente en tres fuentes, a saber: la lógica, el análisis geométrico y el algebra. Descartes (1999) había encontrado que en lo tocante a la lógica aristotélica, ésta solo servía para defender verdades y no para encontrar nuevas. Y, en cuanto al algebra, consideró que ésta solo se ocupaba de abstracciones y su valor práctico era casi nulo. El nuevo método busca conciliar las virtudes de estos saberes desechando sus defectos.

Dicho método quedará sistematizado de la siguiente manera:

1. Duda: Es el punto de partida del método ya que será necesario cuestionar todo cuanto se presente a nuestros sentidos. Al respecto dice Descartes (1999):
No aceptar jamás ninguna cosa por verdad que yo no conociese evidentemente como tal, es decir, evitar cuidadosamente la precipitación y la prevención; y no incluir en mis juicios nada más que lo que se presentara a mi espíritu tan clara y distintamente que no tuviese ocasión de ponerlo en duda.( p.37).

Deja claro que el primer paso del método cartesiano es una reacción al error inherente del sujeto.

2. Análisis: "Dividir cada una de las dificultades, que examinare, en tantas partes como se pudiera y se requiriera para resolverlas mejor" (Descartes, 1999, p.37). Consiste este paso en el fraccionamiento del objeto al máximo, este paso sigue dirigido a purgar el error del sujeto. Cada fracción de realidad será un objeto de conocimiento con identidad propia y susceptible de ser abordado por el método. Este segundo escaño del método trae como consecuencia una renuncia al saber omnicomprensivo griego y le da paso a una nueva forma de razón, la racionalidad especializada.

\section{De lo simple a lo complejo:}

Conducir ordenadamente mis pensamientos, comenzando por los objetos más simples y más fáciles de conocer, para ascender poco a poco, como por grados, hasta el conocimiento de los más compuestos, e incluso suponiendo un orden entre los que no se preceden naturalmente unos de otros (Descartes, 1999, p.38).

Este paso consiste en avanzar comedidamente de las cuestiones más simples a aquellas que están compuestas por más partes o complejas, este paso es la complementación del análisis, análisis que deshizo la compleja dificultad en elementos o naturalezas simples. Ahora, recorriendo estos elementos y su composición, volvemos, de evidencia en evidencia, a la dificultad primera en toda su complejidad. De esta manera consiguiendo verdades que convertidas en reglas servirían para encontrar otras verdades. 
4. Revisión: "Hacer en todo, enumeraciones tan completas y revisiones tan generales que estuviese seguro de no omitir nada". (Descartes, 1999, p.38). De esta manera Descartes plantea su método, iniciando con una duda general y terminando con la certeza propia de las matemáticas, el problema de la verdad queda reducido a una cuestión técnica; la falsedad o la veracidad depende del seguimiento riguroso de este método y lo que llamaremos "Ciencia de la modernidad" será la forma metodológica de abordar un objeto predeterminado de conocimiento siguiendo las reglas de la duda metódica para limitar o depurar el error, aún cometido detectarlo y superarlo, llegando a un resultado que siendo fiel con el método, derivará en una verdad.

En este orden de ideas, la cientificidad queda reducida al seguimiento estricto de este método, y al final llegando a una certeza de haber conocido, certeza conseguida, limitando al sujeto en todos sus procesos de conocimiento, por medio de controlar al máximo el error inherente en él.

Por ejemplo, un niño instruido en aritmética habiendo hecho una suma según sus reglas, se puede estar seguro que encontró sobre la suma que examinaba, todo lo que el espíritu humano podría encontrar. Pues finalmente, el método que enseña a seguir el verdadero orden y a enumerar exactamente todas las circunstancias de lo que se busca contener todo lo que da certeza a las reglas de la aritmética (Descartes, 1999, p.40).

De esta forma ya en el siglo XVII con los trabajos de Descartes y posteriormente con los de Newton (entre muchos otros), quedaba conformada lo que llamaremos "ciencia de la modernidad". Una ciencia que observa, clasifica y organiza los fenómenos; a partir de éstos, consigue verdades 0 principios intermedios que servirán para llegar a verdades que funden principios más generales y abstractos, es decir, leyes científicas.

En este orden de ideas la ciencia de la modernidad era determinista, es decir, a partir del establecimiento de leyes científicas era posible determinar y predecir cómo se iba a comportar la naturaleza en el futuro.

Otra de las características nodales de la ciencia de la modernidad y que no podemos perder de vista, es que todo este proceso de desarrollo científico se está dando en medio del nacimiento y desarrollo de la burguesía y la visión liberal del mundo y de las cosas; el liberalismo en su dimensión económica es capitalista, luego entonces, la ciencia naciente necesariamente tendría que estar al servicio de la nueva sociedad que la estaba gestando, la sociedad burguesa.

En concordancia con la relación de la ciencia y el nuevo modelo de sociedad que emergía, a saber, la burguesía, el barón de Verulam, Francis Bacón, emprendió un grandioso proyecto llamado Instauratio Magna compuesto por una división de las ciencias, un Nuevo Órganon para la interpretación de la naturaleza y culminaba en la sistematización de una filosofía segunda o ciencia activa.

En lo tocante al Nuevo Órganon, Bacón (1984) encuentra que la lógica aristotélica solo sirve para establecer discusiones verbales y vencer al adversario con argumentos creíbles, la lógica que propone Bacón es una lógica no para vencer al adversario sino para vencer a la naturaleza. La lógica en uso (aristotélica), es mas propia para conservar y perpetuar los errores que se dan en las nociones vulgares que para descubrir la verdad; de modo que es más perjudicial que útil (p.34). De esta manera el varón de Verulam mostraba que la lógica aristotélica no era el instrumento adecuado para una verdadera ciencia ya que no encontraba verdades, el segundo argumento descalificador de su parte hacia la lógica aristotélica fue la inducción ilegítima que esta lógica usaba, dice Bacón que la lógica antigua partía de sensaciones y de hechos particulares y se elevaba rápida y precipitadamente a principios generales.

Había comenzado Aristóteles por establecer principios generales, sin consultar la experiencia y fundar legítimamente sobre ella los principios, y después de haber decretado a 
su antojo las leyes de la naturaleza, hizo de la experiencia la esclava violentada de su sistema; de manera que a este título, merece aun más reproches que sus secretarios modernos(los filósofos escolásticos) que han olvidado la experiencia por completo (Bacón, 1984, p.54).

Así, Bacón mostraba cómo la lógica aristotélica era insuficiente como método para obtener una ciencia fecunda, fecundidad que se traduce en un concepto de ciencia activa, es decir una técnica aplicada a la teorización de las leyes científicas. La sociedad burguesa entabla pues un enlace entre ciencia y técnica o tecnología capaz de ser traducida en un entendimiento de la naturaleza para un posterior dominio, dominio que a su vez se convierte en capital, fin último de la sociedad burguesa, esta es una prueba sobre la dependencia que tiene el concepto de ciencia al concepto de cultura y sociedad, la ciencia siempre estará determinada por la sociedad que la engendre.

\section{PROCESO DE "CIENTIFIZACION" DEL DERECHO}

En pleno siglo XVII si existió algún tipo de fe, esa era la que se sentía por la diosa razón, el método de Descartes que nos servía para dirigir correctamente la razón y encontrar la verdad de las ciencias traía como consecuencia la descalificación de todo tipo de saberes que no se acomodaron a este tipo de racionalidad, es decir lo racional se reduce a aquello que es matematizable, medible, observable y en últimas ser susceptible de ser expresado por medio de una ecuación, es decir, la nueva concepción de realidad queda limitada a hechos de la naturaleza(physis), hechos que son observables y medibles para luego expresarlos por medio de leyes científicas generales. En este sentido todo conocimiento que no sea reductible a un número y que vaya más allá de la observación prescindiendo de ella, quedará clasificado como un conocimiento especulativo que, además, se quedaba fuera del paradigma de la época, la razón cartesiana.

En este orden de ideas, uno de esos saberes que no encajaba en el nuevo concepto de ciencia naciente era el derecho. A grandes rasgos ello se debe a tres razones fundamentales: ${ }^{\text {era }}$ ) El derecho romano era una expresión religiosa, la etimología de la palabra IUS alude a un concepto netamente religioso, el IUS era el dicho de IOVE o Júpiter, dicho que prescribía la forma como Júpiter quería que se organizara la civita romana, lo que prescribe dios para los hombres, el proceso judicial romano develaba además la naturaleza religiosa del IUS, era un proceso litúrgicamente pensado y el resultado de dicho proceso era lo que IOVE, Júpiter o dios había prescrito para el caso. $2^{\text {da }}$ ) La fuente primaria de creación y aplicación del derecho era la jurisprudencia, es decir, el pretor romano era el guardián del ius o mensaje de iove y éste era el encargado de interpretarlo y su dictum equivalía al dictum de los dioses, el pretor romano era aquella persona en la que confluían dos calidades éticas, conocía la tekne ${ }^{4}$ del IUS y además tenía la Prudentia ${ }^{5}$ para aplicarlo correctamente, así pues, la jurisprudencia era la fuente primordial de derecho en el acaecer jurídico romano, creaba las "actio" que servían como instrumento del ciudadano romano para pedir el dicho de IOVE en determinado caso y además creaba las máximas, que en términos generales eran reglas de interpretación de las reglas. $3^{\text {era }}$ ) Posteriormente con la actividad compiladora de los glosadores y pos glosadores, se dio un proceso de textualizacion del IUS, no obstante estos textos jurídicos no tenían una sistematización lógico-deductiva, que le mereciera el nombre de sistema. THEODOR VIEHWEG en su libro TOPICA Y JURISPRUDENCIA analiza esta característica presente en el Corpus luris Civile y toma como ejemplo una parte del Digesto de Juliano, concluyendo que se trataba de una compilación de casos particulares y problemáticos.

\footnotetext{
${ }^{4}$ Termino griego que hace referencia a un conocimiento inicial y práctico sobre algún objeto de conocimiento. En Aristóteles aparece este concepto como un hábito de crear por reflexión racional., es traducido al latín como Ars.

${ }^{5}$ Es el término con el que los romanos tradujeron la Phronesis originaria del mundo griego, la palabra hace referencia a una condición ética de mesura, de templanza, de salud del espíritu. En Aristóteles aparece como un instrumento de la filosofía práctica de saberes que no aspiran a ser apodícticos, pues su objeto es lo justo.
} 
Este texto posee sin duda alguna un nexo lleno de sentido, que no es sistemático, sino puramente problemático. Se ofrece en él una serie de soluciones a un complejo de problemas, buscando y fijando puntos de vista, que no aparecen únicamente aquí, sino que proceden de otros grupos de textos parecidos, donde han encontrado ya reconocimiento y comprobación (Viehweg, 1997, pp.75-76).

Este carácter problemático también se devela en el Mos Italicus ${ }^{6}$ y en la jurisprudencia medieval.

Así pues, el derecho anterior a la modernidad era un derecho con rasgos litúrgico-religiosos, la modernidad es chocante con la concepción de fe y religión, consecuencia del paso del teocentrismo al antropocentrismo; además, se trata de un derecho operado jurisprudencialmente, es decir, un derecho que opera subjetivamente por cuanto el pretor es quien lo crea y lo aplica, este es otro aspecto discordante con la modernidad porque el método cartesiano aparta totalmente el sujeto del objeto y reduce lo subjetivo a lo irracional, de esta manera la jurisprudencia cartesianamente hablando es irracional y por último la falta de sistematización de los axiomas jurídicos hacía imposible que este modelo de derecho encajara dentro de la cientificidad moderna.

La empresa que se iba a llevar a cabo por parte de los filósofos del derecho moderno era encuadrar a como diera lugar el concepto de derecho en el de ciencia.

Gottfried Wilhem Leibniz una vez culminado su estudio de Mos o More italicus en la facultad de Leipzig, se ocupa del estudio de la jurisprudencia en su Dissertatio de arte combinatoria, donde pretende conciliar el tradicional estilo de la edad media con el matemático del siglo XVII, Leibniz no propone un destierro total de la tópica pero propone que ésta sea controlada aritméticamente, es decir, matematizar la tópica y la jurisprudencia. Lo que quiere poner de relieve VIEHWEG (1997), cuando le dedica un capítulo de su libro a esta pretensión de LEIBNIZ, es como un joven de 20 años después de terminar sus estudios filosóficos y jurídicos le fue fiel al modelo científico de la época, finalmente fracasó en su intento debido a la vaguedad y ambigüedad del lenguaje usado por la jurisprudencia y la precisión del lenguaje de la lógica axiomática, y su evidente incompatibilidad.

Este es solo uno de los múltiples ejemplos del proceso desesperado de cientifizar el derecho, otro ejemplo, es el de CRISTIAN WOLFF quien intentó hacer una síntesis entre iusnaturalismo y matemáticas, otro ejemplo es HUGO GROCIO quien en 1625 publica su obra capital De jure beli ac pacis, el punto de partida de esta obra es la asimilación de lo natural con lo racional, a partir de ahí elaboró sus teorías jurídicas y políticas con espíritu geométrico, apartándose de lo particular y apelando a lo universal, "así como los matemáticos consideran las figuras abstractas de los cuerpos, yo declaro querer tratar el derecho, prescindiendo de todo hecho particular"(Grocio, 1625 citado en Abbagnano,1995,p.50).

Finalmente, después de la aparición de muchos métodos jurídicos con el fin de objetivar y cientifizar el derecho, en el siglo XIX, se va a desarrollar en la Francia revolucionaria una corriente de pensamiento jurídico que va a intentar reproducir una ciencia objetiva puesta en la naturaleza y separada del subjetivismo humano. Estamos hablando de LAESCUELAEXEGÉTICA.

Para la corriente exegética el derecho es el derecho positivo (positum) o puesto, esta escuela aparece en Francia y su objeto de estudio es el Código Civil Napoleónico de 1804, que representa una obra legislativa acabada, cerrada, no necesita de explicación y responde a todos los problemas jurídicos posibles (Kaufmann: 2002). Como el fin último era poner el derecho en el mundo y que éste a su vez fuera susceptible de ser conocido, la escuela exegética asimilará el derecho a la ley, al código civil. De esta forma quedaba resuelta la

${ }^{6}$ Entendemos por Mos Italicus el intento de reconstrucción del Derecho Romano en su forma más pura, purgándolo de lo que los canonistas le habían incorporado. En el siglo XV, terminó siendo aceptado por la Iglesia. 
cuestión del objeto de conocimiento del derecho, el derecho sólo se encuentra en la ley, todo lo que esté fuera de la ley dejará de ser llamado derecho, a su vez las normas que se encuentran plasmadas en dicha ley son tratadas como verdades lógicas que sólo podrán ser aplicadas racionalmente en el entendido cartesiano (Mercado, 2001). En este orden de ideas aparece el principio de legalidad como principio constitutivo de la ciencia jurídica moderna. Con respecto a lo anterior sostiene Ferrajoli (1997):

El principio de legalidad sirve de fuente de legitimación de las normas vigentes, y por otra parte de las válidas, es efectivamente constitutivo del moderno estado de derecho; en cuanto principio de reconocimiento de las propias normas como empíricamente dadas 0 positivas, es constitutivo de la moderna ciencia del derecho como disciplina empírica 0 positiva, a la que sirve para determinar y al mismo tiempo circunscribir su objeto. (p.67).

En el principio de legalidad quedaba contenido todo lo que significaba derecho, de esta forma el Código Civil de Napoleón era un sistema completo, sin lagunas o vacios, coherente, sin antinomias y univoco, desprovisto de ambigüedades. Ello significa, en primer lugar, que todas sus disposiciones contienen una regla clara; en segundo lugar, se presume que el código es completo en el sentido en que regula de manera total todas las posibles situaciones que puedan surgir en la vida civil de las personas, dejando inocua la necesidad de ejercer labores de integración del derecho; y tercero, dado que el código es coherente se presupone que no hay antinomias entre las distintas normas que los componen. (López, 2004).

Pero cómo se debería comportar el juez ante un sistema tan perfecto y tan bien estructurado como el Código Napoleónico. Bien sabemos que la jurisprudencia es subjetiva y lo subjetivo en términos cartesianos no es científico, por este motivo la escuela exegética va a hacer de la relación norma-sentencia un mecanismo a prueba de apreciaciones del juez (Mercado,2001), es la misma ruptura del sujeto cognoscente- realidad cognoscible y el proceso de aplicación del derecho queda reducido a un proceso silogístico donde el juez solo va a comparar premisas, siendo la premisa mayor la ley, la menor el caso particular fáctico además previsto por la ley y la conclusión de esta subsunción viene determinada de antemano por la propia ley, la conclusión que resulta después del proceso silogístico-deductivo es la única posible por estar contemplada en la ley, y por lo tanto se llega a la verdad jurídica. Una justificación políticojurídica de esta forma de operar el derecho es la deificación de la figura del legislador, "el legislador es sabio y no se equivoca", legislador que es elegido por el pueblo soberano y representa esa soberanía popular, soberanía que no puede ser desconocida por el juez que entre otras cosas no es elegido por el pueblo, en virtud del principio de la separación de poderes introducido por el liberalismo clásico. El juez según la escuela exegética no es más que la boca de la ley, fórmula parecida a la que trae el artículo 230 de la constitución nacional ${ }^{7}$.

Sentadas las anteriores premisas queda develado que en la escuela exegética se condensan todos los intentos por hacer del derecho una ciencia cartesiana, sus tres intentos básicos fueron: $\left.1^{\circ}\right)$ Objetivar el derecho en la ley. $2^{\circ}$ ) Apartar la subjetividad del juez, ya que el juez es un sujeto y el sujeto es proclive al error. y, $3^{\circ}$ ) Hacer del código un sistema lógico-deductivo de tal manera que la ley (voluntad política) contenida en él, cumpla con todos los requisitos de una ley científica, la de ser generaly abstracta.

Todo este esquema planteado por la exégesis colapsaría por múltiples razones que no es objeto de este ensayo explicar, sólo haremos mención a unas cuantas razones, entre ellas, la vaguedad y ambigüedad inherente al lenguaje que se hizo más evidente en la generalidad y abstracción de la ley,

\footnotetext{
${ }^{7}$ Artículo 230. CN: Los jueces, en sus providencias, sólo están sometidos al imperio de la ley. La equidad, la jurisprudencia, los principios generales del derecho y la doctrina son criterios auxiliares de la actividad judicial
} 
vaguedad del lenguaje que imposibilitó en muchos casos la aplicación de la ley y la resolución del caso, dejando sin sustento la supuesta claridad de la ley; $y$, en los casos en que la ley general dejaba de ser clara, debía inevitablemente ser interpretada por el juez; interpretar la norma para aplicarla de alguna manera estaba rompiendo la deducción silogística efectuada por el legislador, que mecánicamente debía aplicar para resolver el caso. También se vio cuestionada la completud del Código Civil, presentándose cada vez más, los casos de las "lagunas del derecho", todos estos problemas entre muchos otros representaron el fracaso filosófico de la exégesis y de todas las corrientes que trataron de elevar el derecho al pedestal de ciencia.

La aplicación del derecho no es sólo, ni lo es en primera línea, una conclusión silogística, lo cual ya no es ningún secreto. Aquellos que todavía hoy sostienen el dogma de la subsunción se asemejan a los fumadores en nuestros días: ellos lo hacen en verdad, pero no encuentran en esto el mismo placer de antes (Kaufmann, 2002, p.113).

Julius Hermann v. Kirchmann (1848) dio su discurso sobre el Carácter acientífico de la jurisprudencia como ciencia, ante la sociedad berlinesa de juristas. KIRCHMANN acusa enérgicamente a los positivistas de haber entregado el derecho a la arbitrariedad y planteó categóricamente que la jurisprudencia no era una ciencia, en sus palabras:

Cuánto mejor sería que la ciencia del derecho pudiera abordar como las ciencias naturales directamente su objeto(...)el sol, la luna y las estrellas brillan hoy como desde hace millones de años, pero el derecho cambia desde entonces (...) si se prosigue la comparación, se descubre una nueva particularidad del objeto de la jurisprudencia en la circunstancia de que el derecho no solo consiste en el saber sino también en el sentir, que la sede de su objeto no se encuentra solo en la cabeza sino también en el pecho de los hombres. Los objetos de otras ciencias (naturales) están libres de este aditamento (...) la ley positiva es, por último un arma inerte y siempre dispuesta, tanto para la sabiduría del legislador como para la pasión del déspota (...) (Kirchmann, 1999 citado en Kaufmann, 2002, p. 129).

Kirchmann deja de presente que el objeto de estudio de la jurisprudencia es cambiante en el trascurso del tiempo y la historia, y que es imposible separar el sujeto, es decir, la jurisprudencia del estudio del derecho ya que el derecho además de razón también es pasión, sentir en sus palabras. Aquí radica el por qué los filósofos actuales no han podido definir al "Derecho", desde el derecho mismo.

La imperfección de la ley es considerada hoy por la mayoría de los juristas como un defecto, y en consecuencia ellos hacen todo para remediar mediante una avalancha legislativa desmesurada. Los que piensan realmente esto mediante contratendencias juridificadoras predican a oídos sordos, y aquellos que están dispuestos a discutir y argumentar en un sistema realmente abierto son, en resumidas cuentas, un pequeño puñado; la mayoría quisiera más bien ligarse a la letra desnuda y rigurosa de la ley y con ello librarse de responsabilidad propia. Ningún riesgo, ésta es la divisa. (Kaufmann, 2002, p.115).

Ante la pregunta por la cientificidad del derecho, un «sí» o un «no» absoluto y definitivo seguramente dejará inalterable las conductas de la comunidad de los dogmáticos jurídicos; la discusión se ha tornado inservible pragmáticamente hablando, estos están dispuestos a "morir" en su postura por que el de ellos, si es derecho.

\section{APROXIMACIÓN A UNA INVESTIGACIÓN JURÍDICA}

En el libro "Técnica y Metodología de la Investigación Jurídica" de Jaime Giraldo Ángel (1985), se plantea el objeto de estudio del derecho en primer lugar, como la de comportamientos humanos que se desarrollan al interior de cada sociedad y que en momentos históricos determinados son de trascendencia para un estado, tal trascendencia lo lleva a la necesidad de una regulación normativa, y en segundo lugar, el estudio de esa regulación desde un punto de vista 
interno, es decir el estudio de la normatividad que reguló determinados comportamientos humanos.

En este sentido existen dos niveles de investigación en el derecho: $1^{\text {ero }}$ ) Un análisis acerca de la formulación de hipótesis normativas tendientes a la resolución de problemas que se desarrollan al interior de una sociedad en momentos históricos específicos encaminados a aspectos políticos, económicos y culturales. A este nivel el análisis va del estudio de la sociedad hacia un contexto de creación jurídica, un contexto de descubrimiento para ser más precisos, este es el objeto de estudio propio de la investigación socio-jurídica. Y, $2^{\text {do }}$ Un análisis de los presupuestos normativos positivizados, es decir, del derecho establecido en virtud de los problemas que le dieron origen. Se trata de una investigación de problemas jurídicos resueltos jurídicamente, problemas de derecho resuelto por las fuentes del derecho. Este es el objeto propio de la investigación jurídica, del cual nos ocuparemos en el presente en ensayo.

\section{LAINVESTIGACIÓN JURÍDICA}

Los problemas jurídicos para efectos de investigación son aquellos que se formulan al interior del mismo derecho, como dijera Bobbio (2005), el problema jurídico producto de la experiencia jurídica en últimas, es un problema normativo. De esta forma el objeto de estudio de la investigación jurídica encuentra su centro de discusión en las fuentes formales del derecho, son estas las que le dan contenido a lo jurídico. Esta primera consideración nos presenta un problema crucial para determinar el objeto de investigación jurídica en Colombia, o lo que es lo mismo, determinar con exactitud cuáles son nuestras fuentes formales del derecho. Al respecto el artículo 230 de la Constitución Nacional es del siguiente tenor: "Los jueces, en sus providencias, sólo están sometidos al imperio de la ley. La equidad, la jurisprudencia, los principios generales del derecho y la doctrina son criterios auxiliares de la actividad judicial". Esta ha sido nuestra tradicional forma de entender las fuentes del derecho, conocida como tradicionalismo de fuentes de tipo formalista; se entiende aquí formalista tal y como lo piensa López
Medina (2006): "el hábito intelectual de los estudiosos de derecho para quienes un problema jurídico se resuelve predominante 0 exclusivamente, mediante el análisis, más 0 menos detallado, de las reglas de origen legislativo que se han promulgado al respecto."(p.266).

No obstante el pensamiento jurídico contemporáneo ha reivindicado de una manera rabiosa el papel de la jurisprudencia como efectiva fuente creadora de derecho, en virtud del giro interpretativo que ha sufrido el derecho (Arango, 1999) y el fracaso de las corrientes que aspiraron a formalizar el derecho y a apartar la jurisprudencia de la experiencia jurídica.

Hasta este punto de reflexión hemos dicho que el objeto propio de la investigación jurídica son las fuentes formales del derecho, donde se deberá dirigir el jurista a la hora de resolver problemas intra-sistema o relevantes para el ordenamiento jurídico.

Con respecto al análisis de las fuentes formales como objeto de la investigación jurídica, es preciso decir que se trata de un objeto contingente que obedece a la interacción cultural de una sociedad determinada, sociedad que se plantea fines y metas que más tarde se condensarán en el derecho, este derecho no va a ser más que un medio para la consecución de esas metas, esto es lo que explica la causalidad invertida propia de las ciencias de la cultura.

Con respecto al método, es menester decir que está determinado por el objeto de estudio, es menester saber el tipo de tela que se va a cortar para saber qué tipo de tijeras utilizar. Abordar el estudio de fenómenos culturales no sólo exige la verificación de su existencia o explicación de sus características, también exige verificar su significado de acuerdo al contexto en que éste se gesta.

En este sentido, siendo el objeto de estudio de la investigación jurídica las fuentes formales, el análisis de estas fuentes oscilara en dos niveles; el primero, consiste en un análisis lingüístico para 
determinar el significado de sus términos, y el segundo, consiste en determinar el alcance de que tiene el significado de esos términos en la sociedad, en concordancia con el fin para el cual se expidió determinada norma. Este doble análisis de la investigación jurídica nos muestra una clara empresa valorativa, empresa que deberá valorar el intérprete, en este orden de ideas, cualquier método que se utilice en una investigación jurídica deberá ser un método interpretativo. Primera consecuen-cia práctica, la forma que asume el método interpretativo dependerá siempre de su intérprete y su formación jurídico-filosófica. Aquí tenemos el problema de la pre-comprensión hermenéutica planteada por Gadamer y que será objeto de una mención breve en líneas sucesivas.

El problema del método en nuestros días ha tomado especial relevancia en la teoría de la ciencia, de tal forma que se ha transformado en el criterio de definición de lo científico; el objeto ha pasado de ser un parámetro de definición de las ciencias a ser un parámetro de división de estas (Neumann,1992,p.353), y según el establecimiento de leyes generales o particulares a partir del estudio de su objeto se dividirán en nomotéticas las primeras e idiográficas las segundas, situado el derecho en la segunda de esta clasificación en virtud del estudio de singularidades y la imposibilidad de establecer categorías universales de sus conceptos; este problema queda develado después que Theodor Viehweg publicara su ya célebre "Tópica y Jurisprudencia", en donde quedó constatado que la jurisprudencia trabaja con base en singularidades, es decir, que su modo de razonamiento es problemático en contraposición al modo de pensar sistemático (Viehweg, 1997).

En este orden de ideas, queda resaltada la importancia del método como garantía de resultados correctos finalizada la investigación.

A la hora de hablar de fenómenos como objeto de estudio de cualquier ciencia, estos aparecen clasificados de la siguiente manera:

Fenómenos naturales: No dependen de la voluntad del hombre sino del acaecer natural, acaecer que es necesario y orientado en cierta medida por la ley de la causalidad efectiva.

Fenómenos culturales: Surgen como producto del actuar humano y además interactuar humano dentro de la sociedad, su acaecer no es necesario sino contingente por depender de alguna manera de la voluntad humana y social, además se encuentran orientados por una causalidad invertida, donde el efecto es anterior a la causa, esto se debe a que su existencia obedece al planteamiento de fines por parte de una sociedad, a partir de esos fines se da una escogencia de medios para su correcta consecución, en este sentido se hace imprescindible el conocimiento de dichos fines para la explicación y estudio de los medios.

Aquí tenemos otra consecuencia práctica a la hora de investigar jurídicamente, es necesario conocer el fin para el cual fue creado el derecho, entendiendo el derecho como un medio por excelencia. Así pues, los fines para los cuales fue creado el derecho le brindan un contexto al texto jurídico, un contexto que es totalmente necesario a la hora de determinar el contenido de las fuentes formales que se pretenden estudiar.

El fenómeno cultural como objeto de la investigación jurídica y la valoración de los fines para los cuales fue creado el derecho, nos muestran que el método apropiado para la investigación jurídica deberá ser un método interpretativo.

Este método interpretativo como ya se había expuesto en líneas superiores, va encaminado a dos puntos nodales de la fuente formal del derecho objeto de estudio, a saber, la determinación de los conceptos lingüísticos empleados por dicha fuente y el alcance de esos conceptos lingüísticos en función de los fines para los cuales fueron expedidos.

Los problemas de interpretación que se pueden presentar al realizar este doble análisis son susceptibles de aparecer tanto en el análisis lingüístico como en la determinación de los fines, pero es en esta última donde los problemas 
interpretativos se hacen más latentes, es lo que Hart(1998) llamará la penumbra o sombra de la norma, hace referencia a la zona gris de la norma en la que se presentan todos los problemas interpretativos, dada la textura abierta de los textos jurídicos, haciendo la aplicación del derecho una necesaria incertidumbre(pp.167-169).

Esta zona de penumbra jurídica necesariamente deberá ser llenada por la labor del intérprete, bien fuera basándose en la voluntad del legislador y la estructura gramatical como un exegeta; bien fuera, interpretando cada fuente como parte de un sistema holístico como un intérprete sistemático; o bien fuera, interpretando la fuente formal del derecho en función de los fines que se plantea una sociedad en su desarrollo cultural, como un sociólogo.

En concordancia con lo anterior, nos dice Jaime Giraldo Ángel (1985): "la interpretación jurídica implica, por tanto, una definición política. Exige asumir una postura en relación con la función del derecho, el proceso de interpretación supone por consiguiente tomar partido por determinada escuela filosófica" (p.87).

Giraldo Ángel sin ser explícito está diciendo que no existe ni puede existir neutralidad a la hora de interpretar textos jurídicos, la investigación tampoco es neutral ya que la sola escogencia de algún método interpretativo predetermina el resultado de la investigación, sumada la personalidad del intérprete que es indivisible en cualquier proceso investigativo, todo ello consecuencia del principio de incertidumbre ${ }^{8}$, en virtud del cual es el investigador quien decide que va a conocer y bajo que parámetros lo va a hacer.

Con Hans George Gadamer (2003) nos introducimos en la hermenéutica o filosofía de la interpretación, donde sujeto y objeto tienen el mismo modo de ser por estar incluidos en el mismo y único proceso de historicidad; así no existe neutralidad en la investigación, ya que el investigador forma parte del objeto de investigación por el sólo hecho de ser un ser puesto y desarrollado en la historia, por lo tanto todo intento de separar racionalidad (objetividad) y personalidad en lo que concierne a las ciencias de la cultura está condenado al fracaso.

En lo concerniente al derecho es menester decir que no es algo inalterable, sino que es acto, y por tanto, no puede ser un objeto que pueda conocerse independientemente de un sujeto. Más bien el derecho concreto es el producto de un proceso de la realización y del desarrollo hermenéutico al interior de una sociedad, realización y desarrollo hermenéutico que se da sólo a través del lenguaje. Así pues, no es posible en absoluto que se dé un carácter correctamente objetivo del derecho fuera del mismo procedimiento de investigación del derecho, y el juez que cree que toma sus criterios de decisión sólo de la ley es víctima de un fatal engaño, pues así sea inconscientemente, permanece dependiente de sí mismo.

Consecuente con las premisas anteriormente sentadas, se puede concluir varios supuestos importantes a la hora de entender el procedimiento investigativo a nivel jurídico:

$1^{\text {ero }}$ ) El método jurídico necesariamente deberá ser un método interpretativo, este método garantizará un resultado que si bien seria atrevido calificarlo de verdad, entre otras cosas por la problemática que representa este concepto a nivel jurídico, bien podríamos calificarlo de razonable, plausible y justificable. En este orden de ideas está pendiente la refinación de una teoría de la interpretación jurídica, hecha antes que por filósofos por juristas,

\footnotetext{
${ }^{8}$ En 1927, el físico y alemán Werner Heisemberg, formuló el famoso principio de incertidumbre, tratando de determinar medidas en un laboratorio sobre los electrones, encuentra un resultado desconcertante. Heisemberg encuentra que por mucho que se esforzase no podía determinar al mismo tiempo la posición y la velocidad del electrón y para poder medir velocidad tenía que renunciar a la posición y al contrario, si quería determinar la posición debía renunciar a medir la velocidad, este principio es una consecuencia de la relatividad de Einstein. A nivel filosófico es de repercusiones profundas: 1.Nuestro conocimiento del mundo está limitado, o se conoce velocidad o espacio. 2 . La determinación o escogencia de un objeto de investigación necesariamente implica la renuncia a otro objeto. 3 . Es el investigador quien en últimas define con intencionalidad que es lo que desea conocer, es decir, el sujeto predetermina su método, su objeto y su resultado.
} 
una teoría de la interpretación amoldada al conocimiento de problemas jurídicos tal, en suma, una filosofía del derecho que aborde los problemas jurídicos, es decir, que los filósofos del derecho sean juristas y no filósofos puros y a secas. (Bobbio, 1980, pp.91-101).

$2^{\text {do }}$ ) Para efectos de investigación jurídica es imposible separar la personalidad del jurista investigador con el objeto de estudio, ya que él forma parte de ese objeto y predetermina el contenido de éste, al pre-comprender los textos jurídicos con la historicidad y formación ética que lleva a cuestas. De esta conclusión se desprende que es necesaria la configuración de una teoría de la antropologíajurídica.

La ontología jurídica tiene la tarea de analizar la constitución del ser del derecho y que solamente en el marco de este cometido se puede analizar la naturaleza del ser humano a partir de fundamentos metódicos. La cuestión de la naturaleza del hombre, de su ser persona, es decisiva para comprender la esencia del derecho, pues el hombre es la medida de todo derecho, la idea del derecho misma (Kaufmann, 2007 p.67).

Así pues entender el derecho supone un entendimiento previo del hombre, hombre que es la esencia de todo derecho.

$3^{\text {ero }}$ ) En virtud del método interpretativo y la indivisibilidad del intérprete a la hora de la investigación jurídica, surge un interrogante bastante interesante. ¿Hasta qué punto esa libertad que tiene el intérprete de escoger un método y de impregnar con su personalidad el proceso investigativo, puede colindar con la arbitrariedad a la hora de presentar el resultado de la investigación o de presentar una decisión judicial?, Una hipótesis para el problema sería la teoría de la argumentación jurídica, de esta forma sólo intuitivamente podríamos afirmar que una completa metodología de la investigación jurídica debería estar compuesta por una teoría de la interpretación, como explicación del contexto de descubrimiento de las decisiones judiciales o de cualquier investigación jurídica y posteriormente por una teoría de la argumentación, desarrollada ya en un contexto de justificación ${ }^{9}$ que seguramente servirá para la legitimación de la libertad interpretativa del investigador, libertad metódica y de injerencia de personalidad inevitables, de esta manera la teoría de la argumentación será una herramienta de legitimación y si se puede decir de racionalización del resultado obtenido.

\footnotetext{
${ }^{9}$ En filosofía de la ciencia se habla de la diferencia entre un contexto de descubrimiento y uno de justificación, de un lado está la actividad de descubrir o enunciar una teoría, actividad que en principio no es susceptible de análisis lógicos, de lo que se trata es de mostrar cómo surge el conocimiento científico, tarea reservada al sociólogo o historiador de la ciencia. El contexto de justificación permea el proceso de validación de la teoría, dicha actividad no solo admite un análisis lógico sino que lo exige, además de otro tipo de análisis; depende el caso, en lo que a interpretación y argumentación jurídica se refiere, se exigirá del juez o investigador jurídico que pase de un contexto de descubrimiento a uno de justificación en aras de interdicción de arbitrariedad y respeto por los derechos y el estado social de derecho. Véase Atienza, Manuel. (2005). Las Razones del Derecho. México: Universidad autónoma de mexico, p. 4-8.
} 


\section{BIBLIOGRAFÍA}

-Abbagnano, N. (1995). Historia de la filosofía, Tomo II. Barcelona: Montaner y Simón.

-Arango, R. (1999). ¿Hay respuestas correctas en el derecho? Bogotá: Ediciones Uniandes.

-Atienza, M. (2005). Las Razones del Derecho. México: Universidad Autónoma de México.

-Bobbio, N. (2005). Teoría General del Derecho. Bogotá: Editorial Temis.

(1980). Contribución a la teoría del derecho. Valencia: Fernando Torres Editor.

-Bacón, F. (1949). Novum Organum. BuenosAires: Losada.

-Descartes, R. (1999). Discurso del Método; seguido de la búsqueda de la verdad mediante la luz natural (dialogo). Bogotá: ed. Panamericana.

-Gadamer, H. (2003). Los caminos de Heidegger. Barcelona: Ed. Herder.

-Giraldo Ángel, J. (1985). Metodología y técnica de la investigación jurídica, 3era ed. Bogotá: Librería del profesional.

-Hart, H. (1998). El concepto de Derecho. Buenos Aires: Abeledo Perrot.

-Kant I. (1987). Crítica de la Razón pura, $7^{a}$ ed. México: Porrúa.

-Kaufmann, A. (2002). Filosofía del Derecho. Bogotá: Universidad Externado de Colombia.

(2007). La Filosofía del Derecho en la Postmodernidad. Bogotá: Ed. Temis.

-Ferrajoli, L. (1997) Derecho y Razón, Teoría del garantismo penal. Madrid: Trotta.

-López Medina, D. (2004). Teoría impura del derecho. La transformación de la cultura jurídica Latinoamericana. Bogotá: Ed. Legis.

(2006).El derecho de los Jueces, 2a ed. Bogotá: Ed. Legis.

-Mercado, D. (2006). Manual de teoría constitucional. Cartagena: Rodríguez Quito editores.

(1998). Aproximación al concepto de ciencia y ciencia jurídica. Colección de estudios jurídicos MarioAlario d'Filippo, 2, 13-51.

(2001) La Interpretación en el derecho. Revista Jurídica, Universidad de Cartagena. 15, 44-81. -Neumann, U. (1992). La teoría de la ciencia jurídica. En A. Kaufmann, -Hassemer W, El pensamiento jurídico contemporáneo (pp.351-364). Madrid: Ed. Debate.

-Viehweg, T. (1997). Tópica y Jurisprudencia. Murcia: Ed. Taurus. 